\title{
EDITORIAL
}

Mikio Shimada - Shogo Okumura

\section{The time is ripe for an English journal from Japan on wood science}

The Editorial Board of the Japan Wood Research Society is appointed every two years. During its tenure, each Board has been dealing with a number of proposals and has done something new to meet various requests. A proposal for publishing a new English journal in addition to the one already established was not an exception. After a long debate based on responses to our questionnaires, the Board of Directors of the Society finally accepted unanimously a new challenge and set down guidelines for publication of the Journal of Wood Science in collaboration with Springer-Verlag Tokyo.

The poll we conducted about recent trends in activities of domestic members has revealed that they are very much interested not only in participating in international meetings in and out of the country but also in making their research reports available globally in a wide variety of international journals. Furthermore, we have learned that there is a strong desire from abroad, including South Asian countries, for having an English journal from Japan. For the benefits of cultivation, preservation, and utilization of sustainable forest resources, the exchange of scientific and technological information on a transnational scale can best be promoted through an international language in this borderless age.

We believe that it is a great undertaking for our Society to publish a new English journal, but such an unprecedented decision has been made with an optimistic, open-minded, and cosmopolitan attitude. Both the present and former Editors-in-Chief of the existing journal are working together in launching a new English journal, hoping that our efforts will be fruitful and, like forest trees, will take root and grow tall.

February 1998

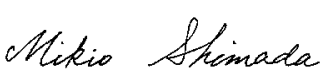

Mikio Shimada

Former Editor-in-Chief

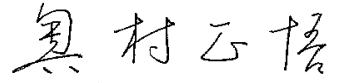

Shogo Okumura Present Editor-in-Chief 